\title{
Retraction Note: Structural strength analysis of loess based on genetic algorithm and the prediction and optimization of coal mine gas emission
}

\author{
Xiumei Xie ${ }^{1,2} \cdot$ Xuedong $\mathrm{Du}^{1,3} \cdot$ Binguo Wang ${ }^{1,3}$
}

Published online: 13 December 2021

(c) Saudi Society for Geosciences 2021

Retraction Note: Arabian Journal of Geosciences (2021) 14: 1539

https://doi.org/10.1007/s12517-021-07923-5

The Editor-in-Chief and the Publisher have retracted this article because the content of this article is nonsensical. The peer review process was not carried out in accordance with the Publisher's peer review policy. The authors have not responded to correspondence regarding this retraction.

The original article can be found online at https://doi.org/10.1007/ s12517-021-07943-1.

Xuedong Du

duxuedong1963@163.com

1 College of Computer Science and Engineering, Shandong University of Science and Technology, Qingdao 266590,

Shandong Province, China

2 Provincial Computer Experimental Teaching Demonstrating Center of Shandong Province, Qingdao 266590,

Shandong Province, China

3 Key Laboratory of Information Technology for IntelligenceMines in Shandong Province, Qingdao 266590, Shandong Province, China 